\title{
An Effective Method In Safety Performance Evaluation For Construction Companies
}

\author{
Liulin Kong1,a, Hanbin Luo ${ }^{1, b}$
}

\begin{abstract}
${ }^{1}$ School of Civil Engineering \& Mechanics, Huazhong University of Science \& Technology, Wuhan, China
\end{abstract}

aemail: kellykong@hust.edu.cn, ${ }^{b}$ email: luohbcem@hust.edu.cn

\begin{abstract}
Keywords: Safety Performance Evaluation (SPE); Holistic approach; Synergy and Symbiosis.
Abstract. Safety standards of construction companies could be improved by continuous monitoring and assessing their safety performance. Despite various methods of Safety Performance Evaluation (SPE) have been proposed, bias or errors can be made by neglecting the inter-relationships among internal variables in SPE. To address it, this paper proposes a synergy and symbiosis based nonlinear methodology to evaluate safety performance of construction companies. A real time SPE system was developed to dynamically monitor and assess the safety performance of construction companies and applied to Wuhan Metro construction sites as a case study. Through this analytical framework, dynamic SPE scores provide good reference to the owner timely, which makes targeted safety control as a parallel activity to the construction rather than an afterthought. Meanwhile it empowers in real time the owners within their decision-making towards a sustainable enterprise orientation. Importantly, construction companies must put more emphasis on safety for improvement in their prestige and future development.
\end{abstract}

\section{Introduction}

Despite continuous efforts have been made to promote construction safety, fatalities still plague the industry [1]. Construction companies undertake all construction activities mainly so that they have the most direct effects on safety performance on-sites. Therefore, it's quite important to measure and evaluate their safety performance to improve safety management and prevent accidents[2].

Safety performance is usually defined as the "overall performance of the organization safety management system in safe operation" [3]. Various safety performance evaluation (SPE) approaches are proposed [4]. For instance, the goal-setting and feedback method [5], Experience Modification Rating (EMR), Incident Rate (IR), Accident Rate (AR) [6], and Score Card (SC) models have been proposed. However, these approaches based on measurement and statistical analysis of incident-related data are often referred to as retrospective or lagging indicators [7]. There are also SPE frameworks which consider factors pertinent to an organization and its projects. For example, [8] built a revised realistic evaluation model with variables as role behavior, leader and worker motivation, underreporting of accidents/injuries, etc. to evaluate occupational safety interventions, etc. [2] applied Structural Equation Modeling (SEM) approach for Prospective (SPE) on three typical types of construction enterprises and compared the differences existing in the safety performance practice regarding different construction enterprise categories. However, these methods are often used separately or complementary and not in an integrated way [7]. In addition, the existing studies centered on safety management stream are largely at the conceptual level and quantitatively oriented based on survey data [4, 9-12] without considering the real time construction safety practices. Further, bias or errors may occur due to the ignored or unproperly addressed inter-relationships among internal variables in most SPE models [2]. Finally, the evaluation results are dealt with using simple arithmetic aggregation or weighting aggregation, which is easy to understand but relationships among every factor are not simple linear complementation.

To put emphasis also on the multidimensionality and the dynamic nature of safety performance evaluation, this paper proposed a novel approach based on theory of Synergistic and Symbiosis (SS) to dynamically evaluate SPE from a holistic perspective. This research applied theory of SS in SPE, 
which can explain the inhibiting relations among different factors and nonlinear relations of interaction among different sub-factors within one factor. The combined relations can be described by Peng' theory as synergetic effect exists within one factor which present complementary relations and symbiotic effect among all factors which present inhibiting relations. The fundamental aim of this study is to apply SS theory based approach to evaluate safety performance of construction companies dynamically. This aim breaks down into the following specific objectives: (1) to build mathematical model of SS theory; (2) to identify principal influencing factors as part of SPE indicators by methods of literature review and formulate a holistic SPE model; (3) to establish measurement scales of SPE indicators used in the proposed model and estimate and rank all of these indicators; (4) to develop a SPE system to monitor and assess the safety performance of construction companies based SS effects; (5) to analyze the validity and availability of the SPE system using a case study.

\section{Methodology}

\section{Theory of synergy}

The score of one factor based on the effect of synergy can be expressed as:

$$
X_{i}=\prod_{j=1}^{n} x_{i j}{ }_{j}\left(\sum_{j=1}^{n} \beta_{j}=1\right)
$$

Where, $X_{i}$ represents the score of factor $i(i \in\{1,2,3 \ldots m\})$;

$x_{i j}$ represents the score of the $j$ th indicator $(j \in\{1,2,3 \ldots n\})$ in the $i$ th factor;

$\beta_{j}$ stands for the weight of the $j$ th indicator in the $i$ th factor.

\section{Theory of symbiosis}

1) Calculation of the practical weight of each performance factor.

Supposing $\alpha_{1}, \alpha_{2}, \alpha_{3}, \ldots, \alpha_{m}$ denote the weight of each performance factor required respectively, $\alpha_{i}$ named ideal weight, and $\sum_{i=1}^{m} \alpha_{i}=1$.

$X_{i}$ denotes the score of the $i$ th safety performance factor, which can be calculated by Equation. (1). Standardize scores of all construction companies and obtain the practical performance weights, represented by $\alpha_{1}^{\prime}$ :

$$
\alpha_{i}^{\prime}=\frac{\alpha_{i} X_{i}}{\sum_{i=1}^{m} \alpha_{i} X_{i}}
$$

2) Calculation of the degree of deviation and maximum degree of deviation

$$
\theta_{\max }=\max \left(\theta_{i}\right)=\max \left(\frac{\alpha_{i}-\alpha_{i}^{\prime}}{\alpha_{i}}\right)
$$

3) Calculation of the modified scores $X_{i}^{\prime}$

Modify the practical scores of each safety performance factor according to $\theta_{\max }, X_{i}$ and $\alpha_{i}$. Assuming the scores and ideal weight of safety performance factor corresponding to the maximum degree of deviation are $X^{*}$ and $\alpha^{*}$, respectively, where $X^{*} \in\left(X_{1}, X_{2}, \ldots \ldots, X_{m}\right) ; \alpha^{*} \in\left(\alpha_{1}, \alpha_{2}, \ldots \ldots, \alpha_{m}\right)$. Then the modified scores of each safety performance factor is defined as $X_{i}^{\prime}$ : 


$$
X_{i}^{\prime}=\frac{\alpha_{i}^{\prime}}{\alpha^{*}} X^{*}
$$

4) Calculation of the overall score $T$

$$
T=\sum_{i=1}^{m} \alpha_{i} X_{i}^{\prime}(i=1,2,3, \ldots, m)
$$

\section{A safety management system for dynamic data collection}

\section{Influencing factors of SPE}

A number of causes influencing safety performance in the construction industry have been identified related to construction companies. Based on existing relevant literatures, a holistic SPE model proposed by [12] was adopted in this research. Policy Factor, Process Factor, Personnel Factor and Incentive Factor $(3 \mathrm{P}+\mathrm{I})$ of safety practices are considered as construction SPE variables.

\section{Overall evaluation process of safety management system}

The safety management system can be defined as the set of persons, resources, policies and procedures that interact in an organized way to reduce damage and losses generated in the process and in the workplace. A well-designed safety management system (SMS) can contribute to the successful implementation of a safety management system in the workplace [17]. Fig.1 demonstrates the monitoring and dealing with construction real time information. As shown in Fig.1, a safety management system based on the SPE model is developed to generate real-time indicators of safety performance with the data transmitted from multiple construction parties. The data is stored in a centralized database in real time for detailed analysis based on theory of synergy and symbiosis by the owner - Wuhan Metro Group Co., Ltd, in China. Therefore, construction parties (e.g. construction company, supervising company, the third safety supervisor, etc.) participating in construction activities of Wuhan Metro lines must implement the SPE system. The SPE system is used as an instrument to measure the degree of implementation of such a process, which integrated ten subsystems such as Decision Support System, Integrated Safety Early Warning System, Video Surveillance System, Potential Safety Hazard Checking System, Emergency Rescue System, Video Conferences System, Big-Data Based Database System, Work attendance System, Quality Management System, and Shield Safe Operating System.

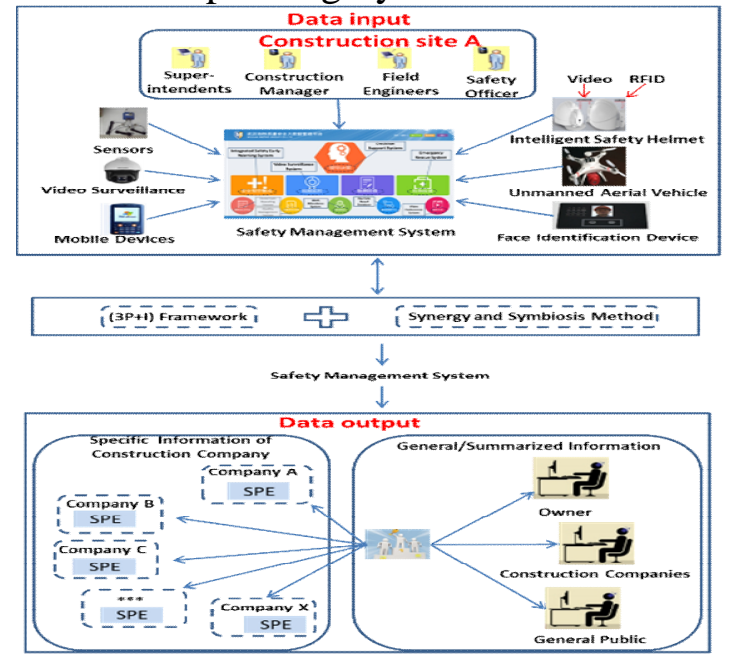

Fig. 1. A SPE system.

\section{Sub-systems for measuring specified indicators}

Taking the safety warning integrated system as an example (shown in the Fig.2), data like strains, stresses, settlement, methane and some other harmful gases are collected by sensors on sites and analyzed by experienced engineers of construction companies (usually construction manager, safety manager and trade site manager) with the output of risk type, number, rank, damage loss related to risk events and corresponding risk control measures. Safety planning in the construction site begins with the identification of safety risks. Therefore, the more comprehensive of identified risk type, 
number, rank, and damage degree of risk, the higher score they get. The risk evaluation result is the safe state of every construction site, which is shown in assorted colours (red means extremely dangerous, orange dangerous, yellow lightly dangerous, and green safe) in the system (shown in Fig.3). The safer state the construction is, higher score it gets. Since the monitoring data on construction sites are changing all the time. Therefore, construction companies must update daily safety reports and weekly safety reports timely, and the more comprehensive of safety reports, the higher scores they get.

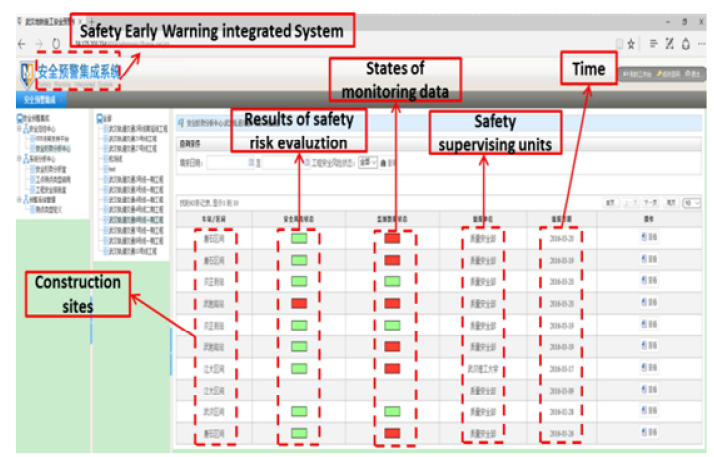

Fig.2. Safe states of stations and sections

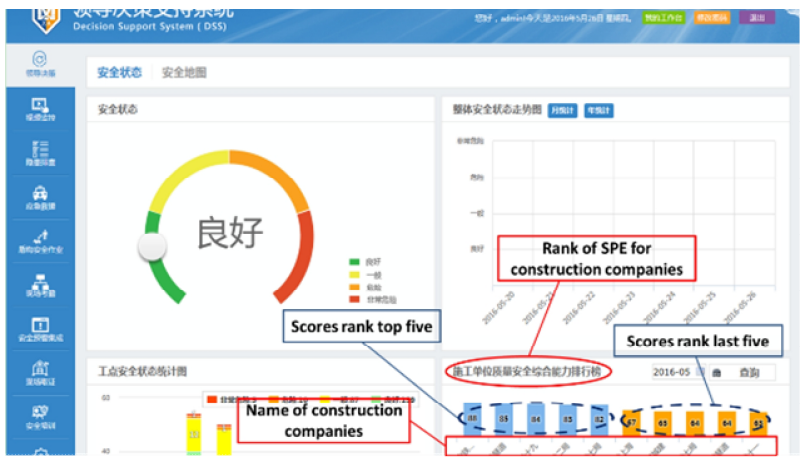

Fig.3. Results of SPE

\section{Case study}

To validate the SPE framework developed in this research, a pilot test in Wuhan Metro construction sites was conducted.

\section{Case background}

To alleviate increasing urban traffic volumes, tunnel construction presents a viable solution for rapid development of China's metropolitan areas in the past 10 years. The total length of urban rail lines in Wuhan is expected to reach $400 \mathrm{~km}$ by 2020 with 14 metro lines being under construction this year. Different construction methods need to meet different safety standards and expectations[12]. There were 20 construction companies engaged in the Metro construction in 2016, such as: China Construction First Building (Group) Co., Ltd, CRSG, Railway tunnel(Group) Co., Ltd, etc. For simplicity, these companies are named as A, B, C, D, E, F, G, H, I, J, K, L, M, N, O, P, Q, R, S and T respectively.

\section{Evaluation process}

Synergy and symbiosis provide a possible way to deal with the complicated inter-relations to evaluate safety performance, which consists of the following three steps:

1) Determine measurable indicators for attributes of SPE model: Descriptions of the above 17 items affecting the construction company's SPE can be measured by corresponding quantified indicators, which is presented in Table 1.

2) Estimate the ideal weights of all the factors and sub-factors: The data then were analyzed according to Mean Ranking and Mean Score as adopted by [19].

3) Implementation of safety management system for real time data collection.

\section{Analysis of results}

Partial score of one factor based on the synergy relationships can be calculated as shown in Table. 1. The system shows final safety performance scores of the top five construction companies and last five ones, which is presented in Fig. 1. According to the results by synergy and symbiosis evaluation method, company D has the highest safety performance, followed by company S, company G, company L, and company $\mathrm{P}$. The last five construction companies are respectively company $\mathrm{M}$, company J, company Q, company $\mathrm{T}$ and company R. While Company $\mathrm{M}, \mathrm{Q}, \mathrm{T}$ and $\mathrm{R}$ all have a disadvantage on policy factors and Company $\mathrm{J}$ has a disadvantage on process factors. The attributes of these factors are most related to proactive and preventive measures for safety management, which may infer that investment in pro-action and prevention is important. Based on the dynamic results of companies' safety performance, the owner can make decisions with targeted safety control towards 
different companies and take right policies towards a sustainable enterprise orientation timely. For construction companies, the low scores of safety performance harm their public images, causing a severe deterioration in the organization's intangibles critical factors in the companies' survival.

\section{Discussion and Conclusion}

If linear evaluation method is adopted, then the overall score $T$ is calculated by:

$$
T=\sum_{i=1}^{n} \sum_{j=1}^{n} \alpha_{i} \beta_{j} x_{i j}
$$

Comparison of results by the two methods are given in Table 2. As Table 2 shows, the results by linear evaluation method are larger than those by synergy and symbiosis method. The traditional linear evaluation method overestimates the real safety performance of construction companies, which takes the void safety performance factors into evaluation neglecting of synergy and symbiosis effects existing among safety performance factors. The overestimated safety performance is related to similarity degree between real structure and ideal structure of safety performance. The $\theta_{\max }(\theta=20.18 \%)$ in company $\mathrm{H}$ is the biggest. Though Company $\mathrm{H}$ achieved high scores in both process factors and incentive factors, the result is not very good. Because it got low scores in policy factors and personnel factors, which will have a symbiosis effect among factors that the strongest factors-incentive factors can't make a full effect on safety performance. The same situation is true in company $\mathrm{O}$ and $\mathrm{R}$. But what different from $\mathrm{G}$ and $\mathrm{H}$ is that the formers have only one obvious $\theta_{\max }$, which causes less symbiosis effect. The results of company $\mathrm{G}$ and $\mathrm{H}$ should be concerned.

The scores by linear evaluation method are 84 and 83 , which are very close to each other. Since the structure of SPE factors in company G is very approximate to the ideal one $(\theta=2.9 \%)$, the score by Synergy and symbiosis method is 84 while that of company $\mathrm{H}$ is 68 . In fact, linear evaluation method takes the ineffective part of factors into consideration, which overestimated the real safety performance of construction companies.

This paper proposes a synergy and symbiosis based nonlinear and develops a SPE system to help evaluate the safety performance of construction companies dynamically. Nonlinear complementary relations are considered among the sub-factors of one factor and inhibition effects among factors. Results show the safety performance of construction companies is mainly determined by its weakest factor and influencing factor of SPE can reflect its actual level only when the levels of all factors are comparatively balanced. Therefore, construction companies have to improve every factor of SPE to achieve high scores of safety performance. To some extent, though factors of safety performance weigh differently in SPE framework, they are equally important in safety management. Any factor related to safety performance must be improved to make better safety management. The results show method based on SS theory gives a new perspective to SPE with more accuracy.

\section{Acknowledgements}

This research is supported by National Natural Science Foundation of China (No.51678265). 
Table 1. Results of safety performance for construction companies.

\begin{tabular}{|c|c|c|c|c|c|c|c|c|c|c|c|c|c|c|c|}
\hline \multirow{2}{*}{$\begin{array}{l}\text { Name } \\
\text { of } \\
\text { comp- } \\
\text { any }\end{array}$} & \multicolumn{4}{|c|}{ The score of safety performance } & \multicolumn{4}{|c|}{ Practical performance weights } & \multicolumn{2}{|c|}{$\begin{array}{l}\text { Maximum degree of } \\
\text { deviation }\end{array}$} & \multicolumn{4}{|c|}{ Modified scores } & \multirow{2}{*}{$\begin{array}{l}\text { Overall } \\
\text { score }\end{array}$} \\
\hline & $X_{1}$ & $x_{2}$ & $X_{3}$ & $X_{4}$ & $\alpha_{1}$ & $\alpha_{2}$ & $\alpha_{3}$ & $\alpha_{4}$ & & & $x_{1}^{\prime}$ & $x_{2}^{\prime}$ & $x_{3}^{\prime}$ & $x_{4}^{\prime}$ & \\
\hline A & 82.34 & 70.34 & 80.83 & 77.37 & 0.318 & 0.244 & 0.229 & 0.209 & $\theta_{2}$ & $9.50 \%$ & 82.34 & 70.34 & 63.42 & 57.66 & 70.12 \\
\hline B & 81.47 & 76.56 & 78.89 & 70.38 & 0.316 & 0.268 & 0.225 & 0.191 & $\theta_{4}$ & $8.89 \%$ & 81.47 & 76.56 & 78.89 & 70.38 & 77.41 \\
\hline $\mathrm{C}$ & 79.11 & 71.73 & 76.36 & 76.97 & 0.312 & 0.255 & 0.221 & 0.212 & $\theta_{2}$ & $5.70 \%$ & 79.11 & 71.73 & 61.89 & 56.26 & 68.83 \\
\hline $\mathrm{D}$ & 89.82 & 87.53 & 87.71 & 84.62 & 0.307 & 0.270 & 0.220 & 0.203 & $\theta_{4}$ & $3.45 \%$ & 89.82 & 87.53 & 87.71 & 84.62 & 87.72 \\
\hline Q & 72.38 & 80.59 & 75.13 & 82.61 & 0.281 & 0.281 & 0.214 & 0.224 & $\theta_{1}$ & $6.42 \%$ & 72.38 & 68.43 & 57.90 & 52.64 & 64.22 \\
\hline $\mathrm{R}$ & 80.79 & 81.10 & 61.89 & 70.72 & 0.325 & 0.294 & 0.183 & 0.199 & $\theta_{3}$ & $17.04 \%$ & 80.79 & 81.10 & 61.89 & 67.64 & 62.84 \\
\hline$S$ & 88.20 & 83.63 & 84.39 & 81.07 & 0.313 & 0.267 & 0.219 & 0.201 & $\theta_{4}$ & $4.21 \%$ & 88.20 & 83.63 & 84.39 & 81.07 & 84.75 \\
\hline $\mathrm{T}$ & 72.55 & 84.54 & 82.87 & 75.55 & 0.277 & 0.290 & 0.232 & 0.202 & $\theta_{1}$ & $7.80 \%$ & 72.55 & 68.10 & 67.62 & 75.38 & 74.07 \\
\hline
\end{tabular}

Table 2. Comparison of SPE by different methods.

\begin{tabular}{|c|c|c|c|c|c|c|c|c|c|c|c|c|c|c|c|c|c|c|c|c|c|}
\hline Company & Name & $\mathrm{A}$ & $\mathrm{B}$ & $\mathrm{C}$ & $\mathrm{D}$ & $E$ & $\mathrm{~F}$ & $\mathrm{G}$ & $\mathrm{H}$ & $\mathrm{I}$ & $\mathrm{J}$ & $\mathrm{K}$ & $\mathrm{L}$ & $\mathrm{M}$ & $\mathrm{N}$ & $\mathrm{O}$ & $\mathrm{P}$ & $\mathrm{Q}$ & $\mathrm{R}$ & $\mathrm{S}$ & $\mathrm{T}$ \\
\hline \multirow{3}{*}{$\begin{array}{l}\text { Linear } \\
\text { evalu- } \\
\text { ation } \\
\text { meth- } \\
\text { od }\end{array}$} & $X_{1}$ & 82.45 & 81.6 & 79.35 & 89.9 & 79.15 & 72.25 & 82.1 & 66.5 & 88.9 & 76.05 & 78.05 & 89.6 & 65.1 & 87.05 & 86.05 & 85.5 & 73.05 & 81.5 & 88.55 & $\begin{array}{l}72.9 \\
5\end{array}$ \\
\hline & $X_{2}$ & 70.81 & 76.96 & 71.89 & 87.7 & 76.09 & 79.93 & 83.88 & 91.65 & 79.84 & 66.92 & 83.85 & 85.51 & 75.44 & 79.41 & 72.61 & $\begin{array}{l}79.5 \\
9\end{array}$ & 81.15 & 81.7 & 83.93 & $\begin{array}{l}85.2 \\
7\end{array}$ \\
\hline & $X_{3}$ & 80.95 & 78.9 & 76.6 & 87.75 & 71.15 & 80.9 & 90.05 & 92.25 & 71.1 & 70.75 & 72.45 & 79.4 & 66.2 & 74.85 & 84.05 & 89.1 & 76.85 & 61.9 & 84.6 & $\begin{array}{l}83.0 \\
5\end{array}$ \\
\hline \multirow{4}{*}{ SS } & $X_{4}$ & 77.9 & 70.65 & 77.2 & 84.7 & 76.95 & 77.65 & 82 & 87.1 & 68.9 & 67.95 & 82.45 & 78.45 & 75.85 & 82.95 & 80.65 & 76.2 & 82.7 & 71.3 & 81.15 & $\begin{array}{l}76.2 \\
5\end{array}$ \\
\hline & $T$ & 78 & 77 & 76 & 88 & 76 & 77 & 84 & 83 & 78 & 71 & 79 & 84 & 70 & 81 & 81 & 83 & 78 & 75 & 85 & 79 \\
\hline & $T$ & 70 & 77 & 69 & 88 & 74 & 75 & 84 & 68 & 70 & 65 & 77 & 83 & 67 & 79 & 73 & 82 & 64 & 63 & 85 & 64 \\
\hline & $\begin{array}{l}\theta_{\max }( \\
\%)\end{array}$ & 9.50 & 8.89 & 5.70 & 3.45 & 6.30 & 6.66 & 2.90 & 20.18 & 12.10 & 5.39 & 8.10 & 6.77 & 7.25 & 7.63 & 10.23 & 8.39 & 6.42 & 17.04 & 4.21 & 7.80 \\
\hline
\end{tabular}




\section{References}

[1] Zhou Z, Goh YM, Li Q. Overview and analysis of safety management studies in the construction industry. Safety Science. 2015;72:337-50.

[2] Wu X, Liu Q, Zhang L, Skibniewski MJ, Wang Y. Prospective safety performance evaluation on construction sites. Accident Analysis \& Prevention. 2015;78:58-72.

[3] Hsu IY, Su T-S, Kao C-S, Shu Y-L, Lin P-R, Tseng J-M. Analysis of business safety performance by structural equation models. Safety Science. 2012;50:1-11.

[4] Thomas Ng S, Pong Cheng K, Martin Skitmore R. A framework for evaluating the safety performance of construction contractors. Building and Environment. 2005;40:1347-55.

[5] Duff AR, Robertson IT, Phillips RA, Cooper MD. Improving safety by the modification of behaviour. Construction Management and Economics. 1994;12:67-78.

[6] Tam CM, Fung IWH. Effectiveness of safety management strategies on safety performance in Hong Kong. Construction Management and Economics. 1998;16:49-55.

[7] Sgourou E, Katsakiori P, Goutsos S, Manatakis E. Assessment of selected safety performance evaluation methods in regards to their conceptual, methodological and practical characteristics. Safety Science. 2010;48:1019-25.

[8] Pedersen LM, Nielsen KJ, Kines P. Realistic evaluation as a new way to design and evaluate occupational safety interventions. Safety Science. 2012;50:48-54.

[9] Wesselink R, Blok V, van Leur S, Lans T, Dentoni D. Individual competencies for managers engaged in corporate sustainable management practices. Journal of Cleaner Production. 2015; 106:497-506.

[10] Torner M, Pousette A. Safety in construction--a comprehensive description of the characteristics of high safety standards in construction work, from the combined perspective of supervisors and experienced workers. Journal of safety research. 2009;40:399-409.

[11] Wu C, Fang D, Li N. Roles of owners' leadership in construction safety: The case of high-speed railway construction projects in China. International Journal of Project Management. 2015;33:1665-79.

[12] Teo EAL, Ling FYY, Chong AFW. Framework for project managers to manage construction safety. International Journal of Project Management. 2005;23:329-41.

[13] Frank SA. The origin of synergistic symbiosis. Journal of Theoretical Biology. 1995;176:403-10.

[14] Frank SA. Genetics of mutualism: the evolution of altruism between species. Journal of Theoretical Biology. 1994;170:393-400.

[15] Hamilton WD. Altruism and Related Phenomena, Mainly in Social Insects. Annual Review of Ecology and Systematics. 1972;3 193-232.

[16] WILSON.D.S. The natural selection of populations and communities. Menlo Park,CA: Benjamin/Cummings. 1980.

[17] Ismail Z, Doostdar S, Harun Z. Factors influencing the implementation of a safety management system for construction sites. Safety Science. 2012;50:418-23.

[18] Adebiyi KA, Charles-Owaba, O. E., \& Waheed, M. A. Safety performance evaluation models: a review. Disaster Prevention and Management: An International Journal. 2007;16:178-87.

[19] Assaf SA A-KM, Al-Hazmi M. Causes of delayin large building construction projects. Journal of Management in Engineering 1995;11:45. 